\title{
Defesa nacional e mobilização popular na doutrina militar cubana
}

\author{
Jefferson Euclides Moura Vasconcelos
}

\begin{abstract}
RESUMO: Analiso a organização cubana para a defesa nacional e a guerra, buscando compreender de que forma a mobilização popular é a chave estratégica para garantir a vitória contra inimigos militarmente superiores - considerando, inclusive, que a vitória se efetiva mesmo quando o embate não acontece, uma vez que a correta preparação funciona como elemento de dissuasão do inimigo.
\end{abstract}

Palavras-chave: Cuba. História Militar. Ciência Política. Guerra de Todo o Povo

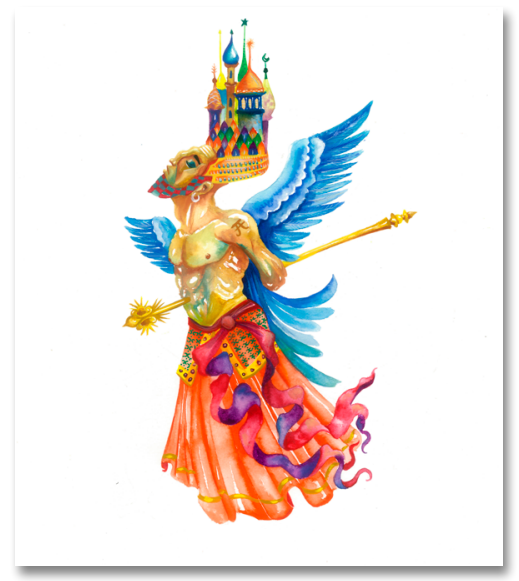

National defense and popular mobilization in the Cuban military doctrine

\section{JefFerson Euclides Moura VASCONCELOS}

Graduando em licenciatura plena em História pela Universidade Católica de Pernambuco (UNICAP). Pesquisador na área de História e Ciência Política, com ênfase em História Militar, Ciência Militar, Estudos Estratégicos e Geopolítica. Email: jvasconcelos12@hotmail.com

\begin{abstract}
I analyze the Cuban organization for national defense and war, seeking to understand how the strategic key to securing victory against militarized superior enemies is popular mobilization - considering that victory is effective even when the clash does not happen, since the correct preparation works as a deterrent element of the enemy.
\end{abstract}

Keywords: Cuba. Military History. Political Science. All People's War

RECEBIDO: 02/03/2018

APROVADO: $30 / 04 / 2018$ 
"Cuba será livre quando a espada redentora lançar ao mar seus inimigos. [...] Mas quem tentar apoderar-se de Cuba recolherá o pó de seu solo alagado em sangue, caso não pereça na luta." (Antonio Maceo)

\section{INTRODUÇÃO}

As palavras desta epígrafe foram proferidas pelo general cubano Antonio Maceo (conhecido como Titã de Bronze, por seu tom de pele acobreado), ainda nos tempos das guerras de independência contra o colonialismo espanhol. Maceo iniciou soldado e alçou ao posto de general e segundo chefe na hierarquia do Ejército Libertador graças a sua valentia, disciplina e gênio estratégico. É uma citação significativa e constantemente rememorada pelo Estado cubano e suas figuras principais, inclusive várias vezes ditada pelo próprio Fidel Castro, graças ao trabalho de valorização da luta pela independência da ilha como maneira de elaborar um panteão nacional e fortalecer a identidade nacional cubana. Encerra em si a premissa mais básica da preparação cubana para a defesa: se o inimigo não cair, nada restará de pé para ser conquistado.

A questão do armamento do povo não é algo recente dentro da história ou da ciência militar, que registra a participação popular em conflitos desde o surgimento das primeiras sociedades humanas. Seria infrutífero empreender uma procura pelo primeiro episódio onde esse elemento teria surgido. Como disse Fidel Castro:

As milícias são tão antigas como as guerras de agressão, são o recurso por excelência a que recorrem os povos para as enfrentar, são uma força especialmente apropriada para a defesa, são os trabalhadores lutando por suas fábricas, os vizinhos defendendo o seu bairro, os cidadãos cuidando de seus bens, os bens do povo, e fazendo prevalecer suas conviçcões e seus ideais. (CASTRO, F., 1981 apud ALVAREZ, 2014, p. 8, tradução nossa).

Interessa-nos o episódio mais conhecido e que marcou o momento em que a questão passa a ser objeto de estudo e análise detalhados. Este segundo aspecto é o que mais salta aos olhos: o fato de ter sido o momento de uma revolução no modo de pensar e fazer a guerra. Falamos do século XIX, quando os exércitos napoleônicos varriam a Europa e os Estados europeus, temerosos pelo seu 
destino, passaram a perceber que uma nova forma de guerrear estava tomando corpo tanto por parte do exército de Napoleão como por parte dos povos que então resistiam à ocupação de seus países, sendo o maior desses exemplos a Espanha ocupada. Héctor Luis Saint-Pierre assim descreve o contexto da resistência espanhola:

[uma vez] Derrotado o exército monárquico espanhol, parte da população civil espanhola tinha se armado para defender o território nacional do invasor estrangeiro. Grupos no começo pequenos, inicialmente mal armados e pior treinados, porém com um grande amor pela Espanha, conseguiam hostilizar as moderníssimas formações napoleônicas sem oferecer frente fixa, sem prolongar os combates, sem uniforme, bandeira e insígnias identificatórias do grupo ou da hierarquia. Comandados por lideranças carismáticas, como "El Empecinado", atacavam as linhas de suprimento e comunicação do exército napoleônico roubando tudo o que podiam, desconcertando e desmoralizando a tropa. (SAINT-PIERRE, 2000, p.151-152).

O próprio Napoleão considerou as dificuldades na Espanha como uma das maiores causas de sua derrota, junto com as campanhas da Rússia. Os teóricos militares do momento passam então a analisar com profundidade o desenrolar dos acontecimentos, com a urgência de formular uma maneira de resistir ao poderoso exército francês. Vejamos:

Os teóricos militares logo perceberam que a única forma de conter ou pelo menos dificultar o avanço das tropas revolucionárias de Napoleão era armar o povo. A teoria de armar o povo para enfrentar o invasor conseguiu motivar o imperador [prussiano] a soltar um édito que conclamava a população a se armar. Mas considerações políticas o fizeram voltar atrás um dia depois: era preferível perder a guerra para uma nação inimiga a ganhá-la ao custo de deixar o povo armado. Todas as classes dominantes temem proporcionar igualdade de condições de luta ao povo oprimido. (SAINT-PIERRE, 2000, p. 152).

O maior expoente dessa tradição prussiana de teóricos militares é o filósofo e oficial de exército Carl von Clausewitz, que em sua 
obra Da Guerra (1832), postumamente publicada, dedica-se, entre outras coisas, a analisar os episódios de resistências populares aos exércitos napoleônicos a fim de formular os princípios desse novo elemento na guerra - ou, segundo suas palavras, da nação em armas. Clausewitz foi um dos primeiros a notar a importância do elemento popular nos conflitos da época, seja como instrumento de resistência ao invasor ou como elemento de coesão interna para que a ação do Estado contra o exército inimigo não se some a uma luta interna contra a população para manter a ordem, ou seja, a dominação. Sobre isso, o historiador, estrategista e major-general do exército britânico John Frederick Charles Fuller diz o seguinte:

Clausewitz foi um dos primeiros a notar a importância disso na guerra de sua época. Assinala ele que, embora a influência de um único habitante no curso de uma guerra seja quase imperceptível, "a influência total dos habitantes de um país está longe de ser insignificante. Tudo vai melhor em nosso próprio país, desde que não encontre oposição no sentimento geral da população" e "a espontânea cooperação do povo é sempre importantíssima". (FULLER, 2002, p. 75).

Diversos outros autores também se dedicaram a analisar como aquela forma de combater da população espanhola fustigava até o esgotamento o exército de ocupação francês. Marx e Engels também se dedicaram ao estudo das guerras napoleônicas. Engels foi carinhosamente apelidado de General por uma das filhas do amigo, graças ao seu gênio estratégico e à familiaridade com a técnica e a teoria militares, por ter prestado um ano de serviço junto à Artilharia da Guarda Real Prussiana e por ter tomado parte em diversos levantes proletários e revoluções derrotadas na Europa. Além disso, trabalhou como correspondente e analista militar para diversos jornais da época. A análise do episódio espanhol ficou a cargo de Marx em uma série de reportagens para o New-York Daily Tribune, sendo ele um dos primeiros analistas do conflito a perceber a importância da guerra de guerrilhas nesse contexto:

não existiam meios para combater radicalmente esse tipo de resistência. Os franceses viam-se obrigados a estar sempre armados 
contra um inimigo que a cada momento fugia e reaparecia, presente em toda a parte e sempre invisível, escondido nas montanhas. (MARX, 1981 apud BUZETTO, 2011, p. 59).

Assim, vemos que o armamento do povo em situações de conflito vem sendo encarado de diversas formas ao longo da história, estando longe de ser uma temática marginal. Não haveria espaço aqui para uma revisão total do tema, nem mesmo para uma revisão dos principais autores. Do ponto de vista político, não faltam exemplos do medo que as classes dominantes ao redor do globo sentem ao imaginar a população organizada em armas, mesmo que seja essa uma condição para a salvação do Estado. Consideram preferível subordinarem-se ao invasor a arriscar serem derrubadas em meio à instabilidade de uma invasão e às possibilidades que essa condição abre para a população, em relação à troca de poder, à ascensão violenta de outro grupo ao comando do Estado ou mesmo às convulsões e revoluções sociais.

Sabendo o potencial que possui uma população quando impulsionada por sentimentos patrióticos e munida das condições materiais que lhes permitam resistir ao invasor, o Estado cubano esforçou-se na formulação de um pensamento orientador das suas instituições destinadas a assegurar a defesa nacional, tendo como base a organização do povo em armas, e não apenas as Forças Armadas. É justamente esse o nosso objeto de análise no decorrer do texto.

\section{OS ANOS 80: REORGANIZAÇÃO DA DEFESA E ELABORAÇÃO DE UM NOVO PRINCÍPIO NORTEADOR}

Chama-se doutrina militar o conjunto de princípios que orientam o Estado e suas instituiçõos para a guerra e a defesa nacional. Abarca o plano teórico, técnico e prático, uma vez que diz respeito à organização de toda uma sociedade para a mobilização em eventuais conflitos e mesmo em tempos de paz. A doutrina cubana, que leva o nome de Guerra de Todo o Povo, é assim definida:

É a concepção estratégica para a Defesa Nacional, que resume a experiência histórica da nação no que toca ao enfrentamento contra inimigos numérica e tecnologicamente 
superiores. Se baseia no emprego mais variado e eficiente de todos os recursos materiais e morais da sociedade, organizados no Sistema Defensivo Territorial, como sustentáculo da capacidade defensiva do Estado. [...] É resumida na afirmação: em caso de uma agressão militar em grande escala contra Cuba, cada cidadão terá um meio, um lugar e uma forma de enfrentar o inimigo até alcançar a vitória. (GUERRA..., [200-?],tradução nossa)

Para entender de maneira ampla esse objeto, precisamos analisar antes de tudo o contexto histórico de sua aparição. A doutrina da Guerra de Todo o Povo surge na década de 80, quando o Estado cubano precisa executar um giro radical na sua política militar graças ao surgimento de um novo cenário. Vejamos que novo fator impulsionou essa mudança.

No ano de 2003, Raúl Castro (CASTRO, 1993 apud LEONOV, 2015), em entrevista ao jornalista Mario Vazquez, relatou pela primeira vez uma reunião ocorrida em 29 de dezembro de 1982, em Moscou, com a presença do presidente do Soviete Supremo e secretário geral do Partido Comunista da União Soviética, do Ministro da Defesa e do secretário do Comitê Central (do PUCS) para as relações exteriores, além do próprio Raúl Castro. Aquele era um momento delicado para Cuba, quando na administração Reagan o então secretário de Estado Alexander Haig, general que serviu nas guerras contra o Vietnã e a Coreia, conduzia uma agressiva política de sufocamento aos movimentos de contestação e revoluções na América Central e pressionava o presidente contra o que considerava a fonte da toda subversão no continente: Cuba.

Conhecemos o desenrolar dessa reunião apenas através da entrevista: a União Soviética deixou claro não estar disposta a intervir em defesa de Cuba no caso de uma agressão por parte dos EUA. Nem mesmo se moveriam para cobrar o compromisso estadunidense assumido em 1962, depois da Crise dos Mísseis, de não atacar a ilha - compromisso esse posto à prova a cada nova administração em Washington. A posição soviética foi mantida em segredo, e as medidas para escondê-la da opinião pública foram bastante eficazes. Sequer os embaixadores soviéticos sabiam de algo, e poucos na administração cubana tinham conhecimento daquele que ficou conhecido como Caso Pandora. 
Aqui, cabe reparar um equívoco. Em trabalho anterior, (VASCONCELOS, 2017), atribuí a um tenente-coronel do exército cubano a citação que declarava que a URSS teria levado a público o seu posicionamento de não defender Cuba em caso de agressão. Até aquele momento, não havia tido acesso à entrevista de Castro, onde este afirma que, uma vez desmembrada a URSS, a Rússia imediatamente pós-soviética não teria condições ou intenção de guardar segredos desse tipo dos EUA. Dessa forma, já que estes passaram a ter acesso à informação, torná-la pública na entrevista não seria prejudicial para a defesa da ilha. Uma vez munido dessa nova fonte, retornei ao texto com a intenção de cruzar as informações e percebi que a ambiguidade dos termos em espanhol fez com que, após a tradução, tal equívoco fosse cometido. Considero necessária a correção para que os leitores não obtenham uma informação incorreta ou que o trabalho do tenente-coronel por mim referenciado seja considerado portador desse engano.

Embora o posicionamento soviético fosse algo esperado por parte dos cubanos, a oficialização coloca na ordem do dia a necessidade de preparar-se sozinho para defender o país, se necessário. É dessa necessidade que nasce a concepção de Guerra de Todo o Povo como aporte teórico para a criação das condições materiais e organizativas que pudessem garantir, por sua vez, a preparação moral, política e técnica para esse tipo de guerra.

A perspectiva de um combate regular é o que norteia a maioria dos Estados existentes hoje. Compreende-se como regular a guerra travada entre exércitos estatais, e que seguem as convenções militarmente estabelecidas no que toca à condução das tropas e do conflito em si. Segue padrões doutrinários rígidos, que teoricamente seriam aplicáveis em qualquer momento, como fórmulas matemáticas preestabelecidas. Diversos momentos ao longo da história serviram para mostrar a deficiência e vulnerabilidade desse tipo de guerra frente a inimigos que combatem de forma não convencional. A resistência espanhola contra o exército de ocupação francês, episódio já citado, é um dos grandes exemplos de como o combate irregular permite enfrentar inimigos convencionalmente mais fortes. 
O caso cubano, por sua vez, apresenta inovações no modo de um Estado organizar-se para a defesa. Existe a total clareza, por parte do núcleo dirigente da ilha, de que um combate convencional contra os EUA estaria fadado à derrota em um curto período de tempo. Não há a possibilidade de vencer a máquina de guerra estadunidense contando apenas com as forças regulares do Estado. Ao balancear a guerra contra o Iraque, o pesquisador alemão Heinz Dieterich, conhecido estudioso da questão militar na América Latina, aponta que:

\begin{abstract}
Um eventual conflito militar de envergadura de Cuba só pode ser resultado de uma agressão direta da potência bélica mais poderosa da terra: a estadunidense. Apesar dos bem elaborados preparativos defensivos das Forças Armadas cubanas, a força aérea, a marinha de guerra e as forças blindadas do país só poderiam resistir um curto espaço de tempo à superioridade numérica e tecnológica estadunidense, tal como ficou evidente na primeira guerra do Iraque. Os aviões de guerra de Sadam que não se refugiaram no Irã, assim como os navios de guerra, foram destruídos muito rapidamente, praticamente sem conseguir infligir dano às forças invasoras.
\end{abstract}

Em Cuba, essa situação não seria muito diferente. As forças regulares serviriam para enfrentar a primeira onda de ataques, mas, em seguida, a guerra se converteria numa guerra de guerrilhas que seria insustentável para o invasor. (DIETERICH, 2004, p. 121, tradução nossa).

A plena consciência dessa deficiência frente às forças armadas estadunidenses é condição indispensável para se organizar de maneira efetiva para garantir a própria defesa. Essa consciência determina um giro de prioridade: o combate não convencional, posto em prática pela população organizada em milícias, é o ponto central da organização cubana para a guerra e a defesa nacional. As forças regulares, em um conflito, serviriam apenas, como diz Dieterich no trecho acima, "para enfrentar a primeira onda de ataques".

Nesse tipo de conflito, a guerra irregular proporciona vantagens de ordem tática e estratégica, quando bem conduzida. O coronel do Exército Brasileiro Alessandro Visacro, atualmente cumprindo 
a função de chefe do Estado-Maior do Comando de Operações Especiais do Exército Brasileiro e reconhecida autoridade nas reflexões sobre a guerra irregular, faz alguns apontamentos:

Em franca oposição à ortodoxia dos soldados profissionais, na guerra irregular predomina a informalidade de táticas, técnicas e procedimentos. Só existe uma regra a ser seguida: "não existem normas, o melhor argumento é o bom resultado". Os princípios cartesianos (quase inflexíveis) que caracterizam a metodologia acadêmica do planejamento militar tradicional são deixados de lado. Decisões cruciais devem ser tomadas com oportunidade em todos os níveis da cadeia de comando, sobretudo pelos escalões subordinados. Assim sendo, ações descentralizadas concebidas segundo um planejamento bem mais flexível, com ordens do tipo "missão pela finalidade", enfatizam a importância de se valorizar ao máximo a iniciativa, a liberdade de ação e a responsabilidade compartilhada. (VISACRO, 2009, p. 248)

Há ainda que se fazer uma consideração chave para entender a questão cubana: na maioria dos casos em que grupos se valeram do combate irregular para alçar ao comando do Estado e uma vez ali estabelecidos, o funcionamento das Forças Armadas seguiu a lógica que lhes era atribuída - a de uma força convencional -, e o Estado seguiu se organizando para o combate regular. Em Cuba, a partir de 1959, uma vez vitoriosa a revolução iniciada através da guerrilha na Sierra Maestra em coordenação com os movimentos estudantis, sindicais etc., foi anunciada a criação das milícias populacionais como forma de garantir tropas que pudessem ser rapidamente mobilizadas em grande número para expulsar qualquer ensaio de invasão, além de equilibrar a balança política no momento em que as forças armadas estavam sendo reorganizadas para atender às aspirações do novo núcleo dirigente. Ainda assim, as milícias não eram até então o centro da política militar na ilha. Isso passa a acontecer apenas com a criação das atuais tropas populares cubanas, as Milícias de Tropas Territoriais, em 1981, passo fundamental dentro da nova lógica criadora da Guerra de Todo o Povo (CASTRO, 1981). A partir de então, as tropas populacionais não mais são apoio das tropas regulares, mas o inverso. 
O Estado passa a se orientar pela centralidade da organização do povo em armas. Na constituição atualmente em vigor, datada de 1992, o artigo terceiro remete à centralidade dessa questão:

\begin{abstract}
Artigo 3. - Na República de Cuba a soberania reside no povo, do qual emana todo o poder do Estado. Esse poder é exercido diretamente ou por meio das Assembleias do Poder Popular e demais órgãos do Estado que delas se derivam, na forma e segundo as normas fixadas pela Constituição e as leis. Todos os cidadãos têm o direito de combater por todos os meios, incluindo a luta armada, quando não for possível outro recurso, contra qualquer um que tente derrubar a ordem política, social e econômica estabelecida por esta Constituição (CUBA, 1992, tradução nossa).
\end{abstract}

O trecho "Todos os cidadãos têm o direito de combater por todos os meios, incluindo a luta armada (...)" é uma das chaves para entender essa estruturação, uma vez que demonstra nossa afirmação anterior de que o centro de sua concepção defensiva não está nas Forças Armadas, mas no povo organizado nas milícias populacionais. Para compreender a doutrina militar cubana, é preciso considerar alguns pressupostos básicos. Dieterich aponta elementos centrais para nossa análise:

A doutrina militar [...] está determinada por seu caráter defensivo-territorial, soberano e baseado nas próprias forças do país, não em alianças militares com outras nações, como por exemplo o Tratado Interamericano de Assistência Recíproca (TIAR). O centro de gravidade dessa concepção de defesa pode definir-se, portanto, como local, auto suficiente e combinado (forças regulares e irregulares) e com um agressor estratégico claramente definido, que é os Estados Unidos. (DIETERICH, 2004, p. 104, tradução nossa).

\title{
3 iAQUí NO SE RINDE NADIE!: A DOUTRINA DE GUERRA DE TODO O POVO
}

Não é incomum encontrar referências que comparam o modelo de defesa cubano a um vespeiro. Esse fato remete à experiência vietnamita de vitória contra inimigos tecnicamente superiores, 
um importante objeto de análise nos momentos de elaboração da doutrina militar cubana. Sob a liderança do presidente Ho Chi Minh e do general Vo Nguy Giap, o Partido Comunista do Vietnã, partindo de um núcleo inicial de 31 homens e três mulheres, fundou o exército que venceria a França, o Japão, os EUA, o Vietnã do Sul, o Camboja e a China em conflitos de intensidades variáveis, sendo a guerra contra os Estados Unidos o mais encarniçado deles. Vejamos o que diz o biógrafo de Raúl Castro sobre a questão:

Da experiência vietnamita se tem conhecimento que entre 60 e $70 \%$ das perdas estadunidenses foram ocasionadas por milicianos locais, e não por enfrentamentos com unidades regulares do Exército Popular da República Democrática do Vietnã. A partir daí que também em cuba se criara o sistema das milícias territoriais, cujas unidades, em caso de necessidade, empunharão as armas e ocuparão as zonas de defesa previamente atribuídas e preparadas para ações combativas (LEONOV, 2015, p. 209, tradução nossa).

Para além da experiência vietnamita, o processo de formulação da doutrina contou com diversos momentos em que era necessário fazer um balanço aprofundado e detalhado de experiências em matéria de resistência à invasão e ocupação de territórios. Foi assim com a resistência soviética ao nazifascismo, a guerra contra a Coreia e, recentemente, a guerra contra o Iraque, entre outros episódios. Mas é da resistência vietnamita que surge a inspiração:

Nasceu e se fortaleceu o conceito de "vespeiro" como protótipo de guerra, em que toda a nação repele o invasor não com a intenção de aniquilá-lo, mas para lhe infligir perdas inaceitáveis e o obrigar a abandonar o território, da mesma maneira que fazem as vespas quando alguém agride seu vespeiro e lhes fincam o ferrão para obrigar-lhes a fugir (LEONOV, 2015, p. 209, tradução nossa).

Esse tipo de preparação exige uma mobilização de grandes proporções, mesmo se tratando de um pequeno país como Cuba. O tenente-coronel Rivera destaca a importância de despertar a consciência dos cidadãos para a necessidade de preocupar-se com a defesa do país: 
A concepção estratégica de Guerra de Todo o Povo tem como objetivo primordial, impedir a guerra ao dissuadir o inimigo. Evitar uma guerra constitui a maior vitória. Para alcançar esse objetivo, de significativo alcance estratégico, é necessário ter organizado e preparado a todo o povo. Nesse sentido o Comandante em Chefe assinala: "Tenham certeza de que quanto mais se prepara o povo, menos perigo tem a Revolução de que lhe ataquem, quanto menos preparado o povo, mais tentados a atacar sentir-se-ão os inimigos da Revolução. Significa que quanto mais investirmos nosso tempo, nossos dias de descanso, nossos sábados, nossos domingos, nossas férias, para nos prepararmos, estaremos contribuindo, desde então, para a vitória da Revolução [...]" (RIVERA, 2006, p. 50, tradução nossa).

Segundo o General de Brigada José Ramón Fernandez, em depoimento sobre o tema,

[...] a concepção de guerra de todo o povo é uma concepção de Fidel. É a filosofia que orienta nossas forças armadas hoje. Nós não pensamos em destruir uma invasão ou um ataque armado de qualquer grande potência - não menciono nomes com apenas as nossas forças armadas. São forças armadas poderosas, mas é necessário todo o povo para golpear um objetivo dessa índole (...) nós podemos armar, de modo organizado e treinado de forma apropriada, muito mais que um milhão de homens. (...). (FERNANDEZ,2006 apud BUZETTO, 2011, p. 254, tradução nossa).

Dados mais específicos indicam que a capacidade de mobilização rápida do Estado cubano, hoje, gira em torno de dois milhões de efetivos das milícias populacionais, somados aos efetivos das forças regulares. Uma vez passado o primeiro momento de emergência, estima-se que quatro milhões e meio de pessoas teriam acesso aos meios materiais para resistir em uma guerra de longa duração, destinada a

(...) dificultar ao máximo a presença do soldado invasor em território nacional. Um dos objetivos principais é criar inúmeras situações que levem o inimigo a conviver cotidianamente com tamanha dificuldade e momentos de tensão permanente, fazendo com que isso aumente consideravelmente o risco de sua sobrevivência. (BUZETTO, 2011, p. 257). 
Em termos técnicos, uma guerra desse tipo exige material simples e de fácil manuseio, que permita sua utilização por uma extensa massa populacional durante um longo período de conflito. Falamos aqui de minas terrestres e explosivos, principalmente. A indústria militar cubana produz uma grande variedade desse tipo de armamento, por seu baixo custo e por sua fabricação ser relativamente fácil. Esse material pode, inclusive, ser produzido pelas Brigadas de Produção e Defesa, organização inserida dentro das Zonas de Defesa responsável principalmente pela logística do combate. As Zonas de Defesa são divisões do território cubano ainda menores que os municípios. Estima-se que algo em torno de 1400 ZDs cubram toda a extensão do território, sendo cada uma munida de grupos que se dedicam a pensar a administração do espaço, a condução logística e o combate naquela unidade territorial. Dieterich aponta que:

Não apenas está organizada a população em milícias, mas também existe um grande número de franco atiradores treinados e com fuzis especiais. Ainda que somente vinte por cento deles conseguisse disparar uma bala contra os invasores, as baixas estadunidenses seriam insustentáveis. (DIETERICH, 2004, p. 121-122, tradução nossa).

Além disso, todo o terreno do país está previamente preparado. Este será, em sua completude, o teatro operacional do conflito, onde não haverá frente ou retaguarda como num embate clássico. No lugar desse modelo, o terreno do combate se organiza como o que Dieterich descreve como "microcosmos defensivos". Preparados para atuar de forma independente e autossuficiente se a cadeia de comando central ruir ante o inimigo, a população conta com uma extensa rede de túneis que abarca todo o território nacional. Esses túneis tiveram sua construção iniciada em 1959, logo nos primeiros meses depois da vitória da revolução, quando a ilha viveu um longo período de ameaças, chegando a sofrer uma invasão promovida por cubanos que fugiram para Miami após a revolução e contavam com financiamento e apoio do governo estadunidense. Esse avanço foi rapidamente reprimido pelas milícias recém-formadas. Vejamos:

Na segunda metade de 1959, o governo Castro começara, a Ilha de los Pinos, a construção de um hospital subterrâneo, à prova de ataques aéreos e de tal maneira encravado na montanha, que um 
avião ou helicóptero não conseguia localizá-lo. A Ilha de los Pinos, onde 35.000 homens viviam em permanente estado de alerta, convertera-se em uma verdadeira fortaleza, com vários subterrâneos e túneis escavados nas montanhas. [...] Só na província de Havana, segundo diversas informações, havia, no mínimo, cinco abrigos antiaéreos, servindo de depósitos de armas e alimentos, e um deles, construído debaixo do Jardim Zoológico, guardava material bélico procedente da Europa Oriental. (BANDEIRA, 2009, p. 372-373)

O trecho descreve a situação ainda no primeiro ano pós-revolução. Quem dirá em que nível se encontra agora a malha de túneis, quase sessenta anos depois? São informações delicadas e mantidas em sigilo quanto a termos precisos, pois dizem respeito à segurança do Estado. Ainda assim, conseguimos ter acesso a alguns dados. Como evidenciam pesquisas recentes, trata-se de uma política de Estado e permanece em curso: "Empreendeu-se a construção de túneis, que continua até o presente, onde se instalaram refúgios para proteger a população e as tropas, assim como preservar os meios de combate e recursos materiais." (LEONOV, 2015, p. 210, tradução nossa). Ou ainda:

Nos anos 1990, por decisão de Fidel Castro e um grupo de oficiais das FAR, iniciou-se a construção de onze mil quilômetros de túneis, para servir de refúgio diante de uma situação de invasão estrangeira. Muitos qualificaram de exagero e mesmo loucura, mas tudo isso fazia parte de uma adaptação da realidade cubana às novas orientações que vinham com a doutrina militar de Guerra de Todo o Povo. (BUZETTO, 2011, p. 260).

Toda essa preparação é posta à prova regularmente por meio de exercícios militares destinados a verificar em que nível se encontra a capacidade de mobilização no caso de uma situação emergencial. É estruturada de forma ao mesmo tempo centralizada pelo Estado, mas bastante descentralizada na medida em que a prioridade é garantir que cada zona seja capaz de agir de forma independente do comando central. A defesa cubana é testada nos níveis locais, regionais e nacionais em meio aos exercícios. O mais amplo desses exercícios é o Ejercicio Estratégico Bastión, regularmente executado, que 
Cobre todo o território nacional e envolve o maior número possível de população regular, reservistas e população geral; representa um momento culminante que nos permite consolidar e valorizar o que foi alcançado, para fazer informações precisas sobre a direção da defesa da nação, tanto em termos de luta armada quanto não armada; é um degrau superior para consolidar a invulnerabilidade defensiva da Pátria. (SERRA, 2013, tradução nossa).

Como diz o título do artigo acima citado, para os cubanos, "evitar a guerra equivale a ganhá-la". Toda a preparação, desde as formulações teóricas até a aplicação prática e sua culminância nos exercícios, funciona como fator desestimulador de qualquer agressão. Não faltam exemplos disso, como em 1982, quando os EUA iniciaram diversas manobras militares no Caribe, mobilizando grande quantidade de efetivos, aviões e navios para ensaiar uma invasão à Cuba que só não se efetivou em decorrência dos cálculos do Departamento de Defesa de que o custo de vida de soldados americanos seria muito elevado. (BANDEIRA, 2009).

Dentro da ciência militar, parece impossível conceber um modelo de defesa que não se organize exclusivamente dentro dos limites das instituições especialmente destinadas para tal. Salvo alguns exemplos limitados, mesmo nos países onde o armamento civil segue padrões menos rígidos que os nossos, a lógica da defesa do Estado segue moldes ortodoxos, ou seja, o combate entre exércitos estatais no esquema convencional. O caso cubano se destaca por ser resultante de um contexto em que o projeto político implantado depois da revolução precisava de garantias de uma não-invasão do oponente geograficamente próximo e militarmente superior em todos os aspectos. Essa garantia, para os cubanos, é a Guerra de Todo o Povo, sua forma particular de organizar o povo em armas.

\section{REFERÊNCIAS}

ALVAREZ, O. M. Milicias de Tropas Territoriales: elgranejército popular de nuestrarevolución. Revista Verde Olivo, Ciudad de La Habana, n. 1, p. 4-9, 2014.

BANDEIRA, M.De Martí a Fidel: a Revolução Cubana e a América Latina. 2. ed. Rio de Janeiro: Civilização Brasileira, 2009. 
BUZETTO, M. Guerra de todo o povo: a influência das lutas políticas e sociais na nova doutrina de defesa nacional venezuelana. 2011. $334 \mathrm{f}$. Tese (Doutorado em Ciências Sociais) - Departamento de Ciências Sociais, Pontifícia Universidade Católica de São Paulo, São Paulo, 2011. Disponível em: <https://sapientia.pucsp.br/bitstream/handle/3317/1/Marcelo\%20 Buzetto.pdf>. Acesso em: 11 maio 2018.

CLAUSEWITZ, C. von. Da guerra. São Paulo: Martins Fontes, 2003.

CUBA. Constituição (1992). Constitución de la República de Cuba. Disponível em: <https://www.parlamentocubano.cu/index.php/ constitucion-de-la-republica-de-cuba/>. Acesso em: 15 maio 2018.

CUBA. Ley número 75 de la defensa nacional, 21 de diciembre de 1994. 1994.Disponível em: <https://www.parlamentocubano.cu/index. php/documento/ley-de-la-defensa-nacional/>. Acesso em: 10 maio 2018.

Colegio de Defensa Nacional. Glosario: selección de términos sobre seguridad y defensa nacional. 2009. Disponível em: <https://www. cubadefensa.cu/?q=glosario>. Acesso em: 15 maio 2018.

CURREY, C. B. Vitória a qualquer custo: a biografia do general VoNguyenGiap. Rio de Janeiro: Biblioteca do Exército, 2002.

DIETRICH, H. La doctrina militar cubana y las lecciones de Irak y Kosovo. In: __ (Org.). La integración militar del bloque regional de poder latinoamericano. Caracas: Instituto Municipal de PublicacionesAlcadia de Caracas, 2004. p. 101-122.

FULLER, J. F. C. A conduta da guerra. Rio de Janeiro: Biblioteca do Exército, 2002.

GIAP, VON.Armamento das massas revolucionárias, edificação do exército do povo. 2. ed. São Paulo: Edições Nova Cultura, 2017.

GUERRA de todo el pueblo. [200-?],Disponível em: <https://www.cubagob. cu/otras_info/minfar/guerra_pueblo.htm>. Acesso em: 15 maio 2018.

LEONOV, N. S. Raúl Castro: unhombreenrevolución. La Habana: Editorial Capitán San Luis, 2015.

RIVERA, TenCel M. I. B. La guerra de todo elpueblo: nuestraconcepción de lucha invulnerable. Revista Verde Olivo, Ciudad de La Habana, p. 47-51, 2006.Edición especial.

SAINT-PIERRE, H. L. A política armada. São Paulo: Editora UNESP, 2000.

SERRA, O. S. Para nosotros evitar la guerra equivale a ganarla. Granma, La Habana,ãno 17, n.321, nov. 2013. Disponível em: <http://www.granma.cu/ granmad/2013/11/18/nacional/artic01.html>. Acesso em: 19 maio 2018.

VASCONCELOS, J. E. Uma introdução à Guerra de Todo o Povo, a doutrina militar do Estado cubano. REBELA - Revista Brasileira de Estudos Latino-Americanos, v. 7, p. 510-528, 2017.

VISACRO, A. Guerra Irregular: terrorismo, guerrilha e movimentos de resistência ao longo da história. São Paulo: Contexto, 2009 